\title{
Alpha-N-acetylgalactosaminidase deficiency type 3
}

INSERM

\section{Source}

INSERM. (1999). Orphanet: an online rare disease and orphan drug data base. Alpha-Nacetylgalactosaminidase deficiency type 3. ORPHA:79281

Alpha-N-acetylgalactosaminidase (NAGA) deficiency type 3 is a rare clinically heterogeneous type of NAGA deficiency (see this term) with developmental, neurologic and psychiatric manifestations presenting at an intermediate age. 